\title{
THE ALLOPOLYPLOID ORIGIN AND GENOMIC CONSTITUTION OF POTENTILLA ANGLICA
}

\author{
B. MATFIELD \\ Department of Botany, Westfield College, London \\ and \\ J. R. ELLIS \\ Department of Botany and Microbiology, University College, London
}

Received 12.i.72

\section{INTRODUGTION}

Potentilla anglica Laich. (= $P$. procumbens Sibth.) is an octoploid species $(2 n=56)$ which is thought to have arisen as the allopolyploid between two tetraploids, $P$. erecta (L.) Räusch. $(2 n=28)$ and $P$. reptans L. $(2 n=28)$. Over a century ago Grenier (1865) recognised the intermediate morphology of $P$. anglica and identified it as the hybrid between $P$. erecta and $P$. reptans. However, Wolf (1901) pointed out that it is fertile and should be given specific status. The theory of allopolyploidy was not applied to $P$. anglica until 1951, when Stomps showed that its chromosome number is equal to the sum of the chromosome numbers of $P$. erecta and $P$. reptans.

$P$. anglica and its putative parents are common species and occur sympatrically throughout Europe. Ecological barriers normally separate the three species but they sometimes meet and hybridise. All three possible hybrid combinations have been reported, but it is doubtful whether the tetraploid hybrid between $P$. reptans and $P$. erecta actually occurs in nature (Matfield, 1972). It has recently been synthesised experimentally (Schwendener, 1969; Matfield, 1972) but previous attempts to hybridise the tetraploid species failed as a result of genetic incompatibility barriers (Brükss, 1931; Matfield, Jones and Ellis, 1970). For this reason confirmation of the allopolyploid origin of $P$. anglica by experimental synthesis has proved difficult.

This paper describes a progeny of polyploid hybrids which were obtained from crosses between induced autopolyploid strains of $P$. reptans and $P$. erecta. The hybrids were morphologically similar to and interfertile with $P$. anglica and can therefore be regarded as "synthetic $P$. anglica". Comparisons are made between meiotic behaviour in $P$. reptans, $P$. erecta and their tetraploid hybrid, the induced autopolyploids and natural and synthetic $P$. anglica. The origin and genomic constitution of natural $P$. anglica is also discussed.

\section{Material AND Methods}

$P$. erecta, $P$. reptans and $P$. anglica were obtained as seed or transplants from wild populations, the localities of which are listed in the appendix. They were maintained in pots sunk into the soil. Auto-octoploid $(2 n=56)$ strains of $P$. reptans and $P$. erecta were induced by colchicine treatment as described previously (Matfield, Jones and Ellis, 1970). Autohexaploid $P$. erecta $(2 n=42)$ arose by hybridisation between the $\mathrm{C}_{0}$ generation octoploids and untreated tetraploids. 
Meiotic preparations were made by the squash technique for pollen mother cells described by Thomas (1940). Buds were fixed for at least a week in acetic-alcohol containing ferric acetate as a pre-mordant and the anthers were squashed in strong aceto-carmine solution. The techniques for somatic chromosome counts and experimental hybridisations have been described previously (Matfield, Jones and Ellis, 1970).

\section{RESULts}

$P$. erecta and $P$. reptans are morphologically very distinct although Wolf (1908) included both in the subseries Tormentillae. The intermediate nature of $P$. anglica is evident from fig. 1 and the polygraph (fig. 2) which shows the relationship between the three species in respect of six quantitative characters. The points on the graph show average values for each species determined from all the plants kept in cultivation. Characters were not recorded until the plants had been in the experimental garden for at least a year in order

TABLE 1

Meiosis in auto-8x P. reptans

$\begin{array}{cc}\begin{array}{c}\text { Number of multivalents } \\ \text { (IIIs or IVs) }\end{array} & \begin{array}{c}\text { Number of P.M.C.s } \\ \text { at MI }\end{array} \\ 0 & 7 \\ 1 & 10 \\ 2 & 16 \\ 3 & 12 \\ 4 & 7 \\ 5 & 4 \\ 6 & 1 \\ 7 & 1 \\ 8 & 1\end{array}$

59

to eliminate environmental effects as far as possible. With the exception of carpel number and flower diameter in $P$. reptans, all values are averages of at least 50 records. $P$. anglica is intermediate in all characters except those directly affected by the difference in chromosome number. Thus the stomata and pollen grains are larger and the length : breadth ratio of the leaflets is lower in $P$. anglica than in the tetraploids.

$P$. erecta and $P$. reptans are both highly fertile but self-incompatible. $P$. anglica, on the other hand, is self-compatible and has an unusually low fertility for a species. Pollen counts made on plants in the experimental garden and in wild populations showed a mean pollen grain stainability of only 62 per cent. with a range of 30 to 92 per cent.

Both tetraploids regularly formed 14 bivalents at metaphase I, tetrad formation was normal and the resultant pollen grains were uniform in size, giving no evidence for non-reduction. The induced autopolyploids formed a proportion of multivalents, as shown in tables 1 and 2 . Auto- $8 x P$. reptans can form a theoretical maximum of 14 quadrivalents, but the observed multivalent frequency was much lower than this, ranging from 0 to 8 with an average of 2.5 per cell. The majority (about 75 per cent.) of the multivalents were quadrivalents, the remainder being trivalents. Secondary 


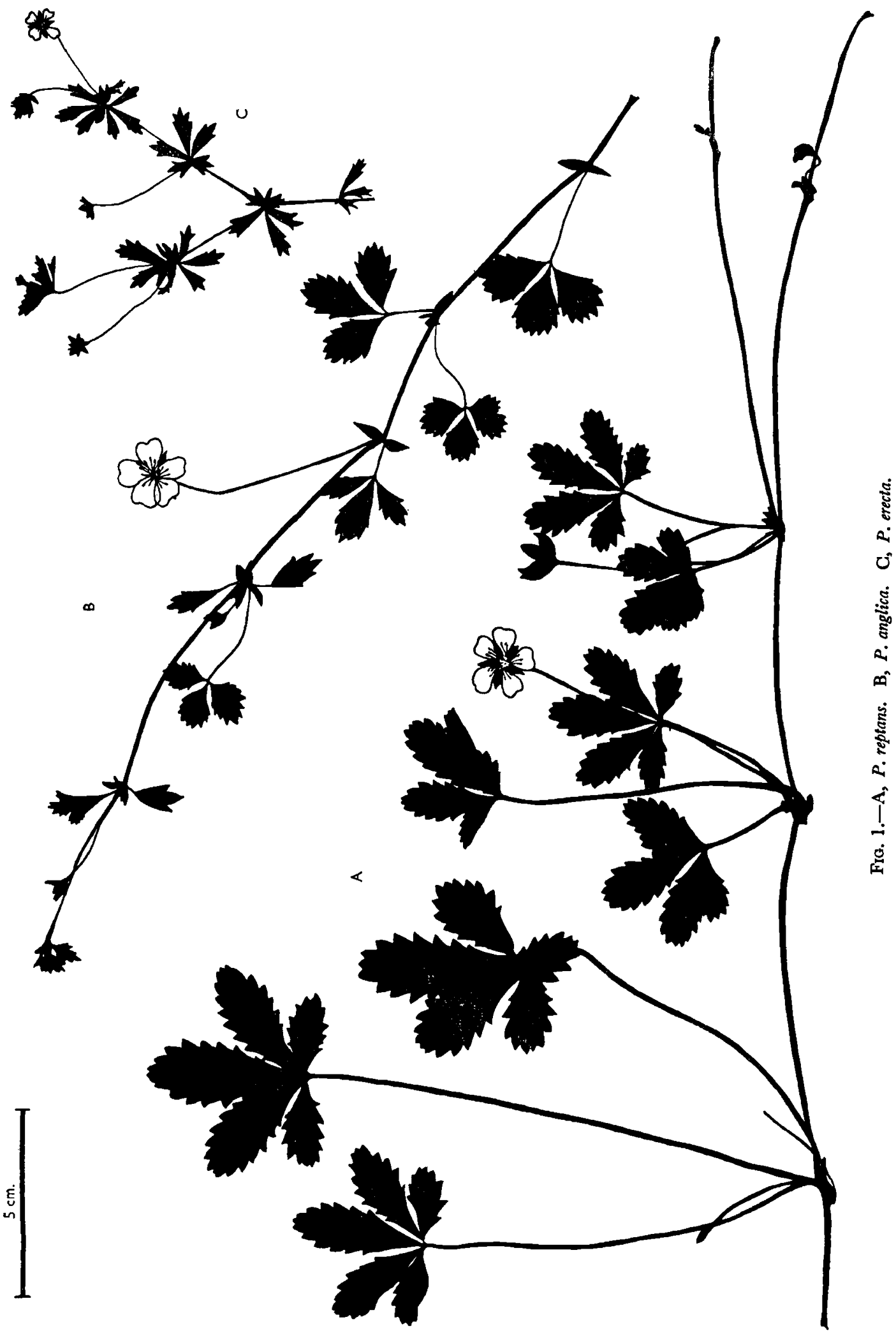




\section{Petiole length $(\mathrm{cm}$.}

(cauline leaves)

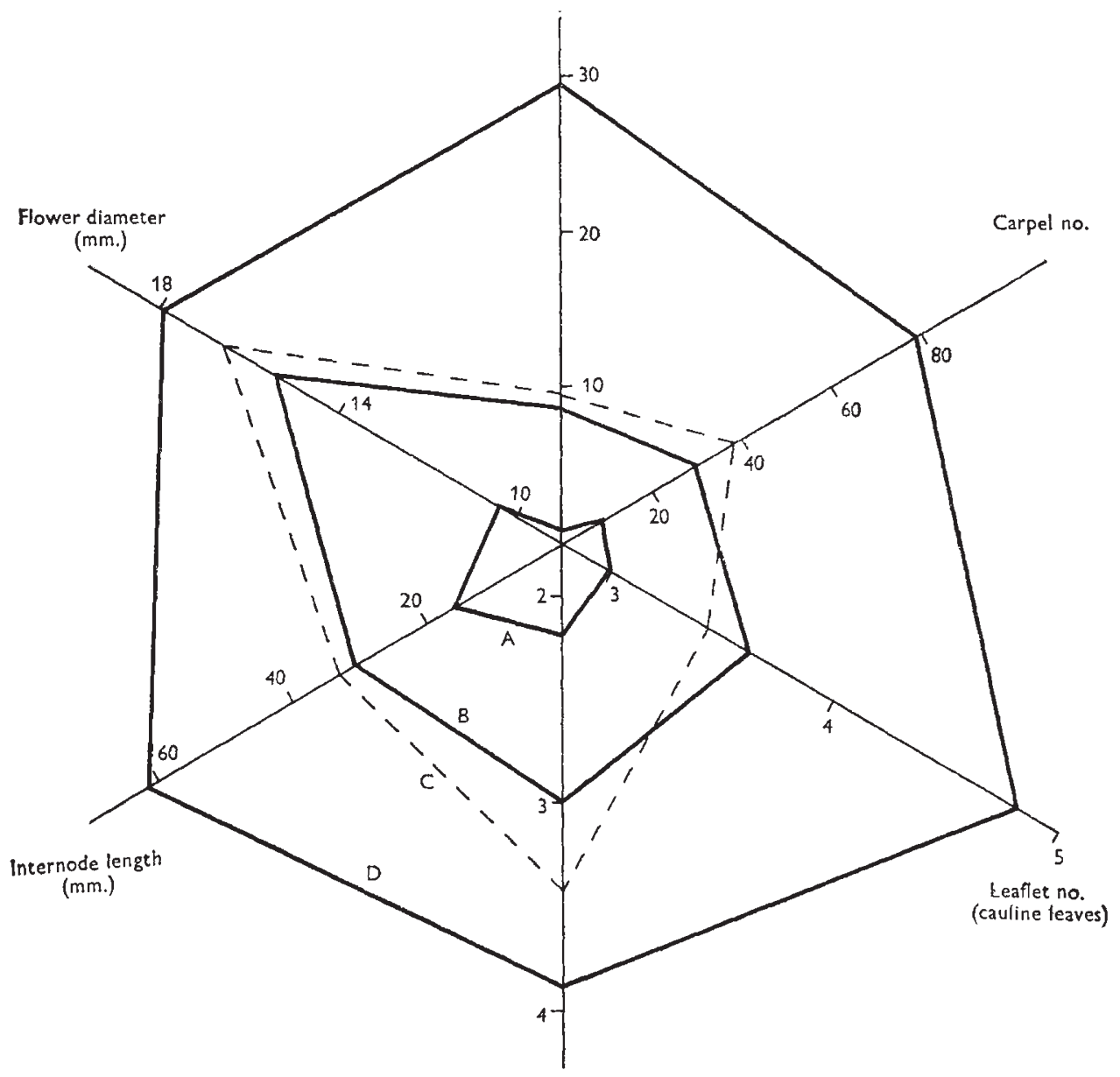

No. of teeth

(cauline leaves, one side)

Fig. 2.-Polygraph showing the comparative morphology of A, $P$. erecta; B, natural $P$. anglica; C, "synthetic $P$. anglica"; and D, $P$. reptans.

TABLE 2

Meiosis in auto-6x P. erecta

\begin{tabular}{|c|c|}
\hline Chromosome pairing & Number of P.M.C.s at M I \\
\hline $8 \mathrm{III}+6 \mathrm{II}+6 \mathrm{I}$ & 1 \\
\hline $9 \mathrm{III}+5 \mathrm{II}+5 \mathrm{I}$ & 0 \\
\hline $10 \mathrm{III}+4 \mathrm{II}+4 \mathrm{I}$ & 3 \\
\hline $11 \mathrm{III}+3 \mathrm{II}+3 \mathrm{I}$ & 8 \\
\hline $12 \mathrm{III}+2 \mathrm{II}+2 \mathrm{I}$ & 15 \\
\hline $13 \mathrm{III}+1 \mathrm{II}+1 \mathrm{I}$ & 15 \\
\hline $14 \mathrm{III}$ & 8 \\
\hline
\end{tabular}


associations were quite commonly observed (plate I, A). The multivalent frequency in auto- $6 x P$. erecta was much closer to the theoretical maximum of 14 trivalents per cell, with a range of 8 to 14 trivalents and a mean of 12.26 per cell. Plate I, B shows a cell with 12 trivalents, two bivalents and two univalents. As a consequence of the high trivalent frequency chromosome segregation was more irregular in auto-6x $P$. erecta than in auto-8x $P$. reptans.

Meiosis in $P$. anglica was fairly regular. The majority of cells formed 28 bivalents, but a small proportion contained a single quadrivalent (table 3 ). Failure of pairing with the formation of two, or in one case four, univalents was seen in 4 per cent. of cells. Plate I, C shows a cell at diakinesis with one chain quadrivalent and a secondary association between two bivalents. It is of interest that Schwendener (1969) observed a much greater degree of meiotic irregularity in $P$. anglica from a British source. Of a total of 59 cells examined, only 22 (37 per cent.) contained 28 bivalents. The remainder contained one to five multivalents and cells with two, four, six and even ten

TABle 3

Meiosis in P. anglica

\begin{tabular}{lccc} 
& \multicolumn{3}{c}{ Number of P.M.C.s } \\
\cline { 2 - 4 } Chromosome pairing & 1 & 0 & Totals \\
26 II + diakinesis & at metaphase I & 1 \\
27 II +2 I & 5 & 0 & 5 \\
28 II & 95 & 28 & 123 \\
26 II +1 IV & 12 & 0 & 12 \\
& 113 & 28 & 141
\end{tabular}

univalents were observed. The reason for this difference in meiotic behaviour between members of the same species is unknown.

Previous attempts to hybridise the tetraploid species failed because of incompatibility barriers (Matfield, Jones and Ellis, 1970). P. reptans pollen did not stimulate seed set in $P$. erecta, and although the reciprocal cross produced many seeds germination was very rare: a total of more than 3000 seeds yielded only one inviable seedling. Subsequently four more pollinations were made using a different clone of $P$. reptans as female parent. Two hundred and twenty-three seeds were obtained and two germinated, but only one seedling survived. This developed into a weak plant, smaller than either parent but otherwise intermediate in morphology.* It was highly, but not completely, sterile. An average of 12 per cent. of the pollen grains stained with aceto-carmine and only one seed was obtained from eight open pollinated flowers. The chromosome number was the same as that of the parental species, $2 n=28$. Meiosis was observed in 103 pollen mother cells (table 4) and more than half of these had regular bivalent pairing. The remainder contained two, four or six univalents, and one cell included a quadrivalent. The mean bivalent number was 13.5. Plate I, D shows a cell with 13 bivalents and two univalents.

Schwendener (1969) obtained three tetraploid hybrids from crosses between Swiss specimens of $P$. reptans and $P$. erecta and examined metaphase

* A full description of this hybrid is published elsewhere (Matfield, 1972). 
I in a total of 202 pollen mother cells. The bivalent number ranged from 3 to 14 and the mean bivalent numbers for the three plants were $13 \cdot 1,12 \cdot 6$ and 10.9. He also observed 11 cells with a single quadrivalent and one cell with two quadrivalents. The meiotic behaviour of the British and Swiss hybrids was therefore very similar.

In an attempt to synthesise the allopolyploid, reciprocal crosses were made between induced auto-octoploid strains of $P$. reptans and $P$. erecta,

TABLE 4

Meiosis in the $4 \times \mathrm{P}$. reptans $\times 4 \times \mathrm{P}$. erecta $F_{1}$ hybrid

$\begin{array}{cc}\text { Chromosome pairing } & \begin{array}{c}\text { Number of P.M.C.s at } \\ \text { diakinesis or MI }\end{array} \\ 11 \text { II +6 I } & 3 \\ 12 \text { II +4 I } & 6 \\ 13 \text { II +2 I } & 34 \\ 14 \text { II } & 59 \\ 12 \text { II + IV } & 1\end{array}$

but no viable seed was obtained (Matfield, 1968). However, a progeny was raised from crosses using auto- $8 x P$. reptans as female parent and auto- $6 x$ $P$. erecta as pollen parent. Thirty-six seeds were obtained and 24 germinated, but 13 died at the seedling stage or soon after. The remaining 11 plants were vigorous and their chromosome numbers ranged from $2 n=43$ to $2 n=56$ (table 5). Plate I, F shows a somatic metaphase from the individual with $2 n=53$. The single octoploid $(2 n=56)$ showed no evidence of hybridity and may have resulted from accidental self-pollination or from the apomictic

TABLE 5

Chromosome numbers of the progeny from crosses between auto-8x P. reptans and auto $-6 \mathbf{x} \mathbf{P}$. erecta

\begin{tabular}{lrrrrrrr} 
& \multicolumn{8}{c}{ Chromosome number } & \\
Number of plants & 43 & 52 & 53 & 54 & 55 & 56 & Total \\
& 1 & 2 & 1 & 3 & 3 & 1 & 11
\end{tabular}

development of an unreduced ovule. The other 10 plants were morphologically intermediate between the parents which confirmed their hybrid origin. The individual with $2 n=43$ differed from the others in morphology and fertility and resembled the natural hybrid $P . \times$ mixta (Matfield, Jones and Ellis, 1970). Its pollen grain stainability was less than 1 per cent. and no seed was set. In contrast, the nine hypo-octoploids $(2 n=52-55)$ were all fertile. Their average pollen stainability ranged from 55 to 83 per cent. and the average number of carpels developing into seeds from 39 to 80 per cent. (table 6). There was no correlation between chromosome number and fertility. Like $P$. anglica, they were self-compatible. The nine plants were quite uniform in morphology and were strikingly similar to natural $P$. anglica. This can be seen from the polygraph (fig. 2) which shows the values for several quantitative characters averaged over all nine plants. Fig. 3 shows a flowering stem from the individual with $2 n=53$ alongside one from natural $P$. anglica. 


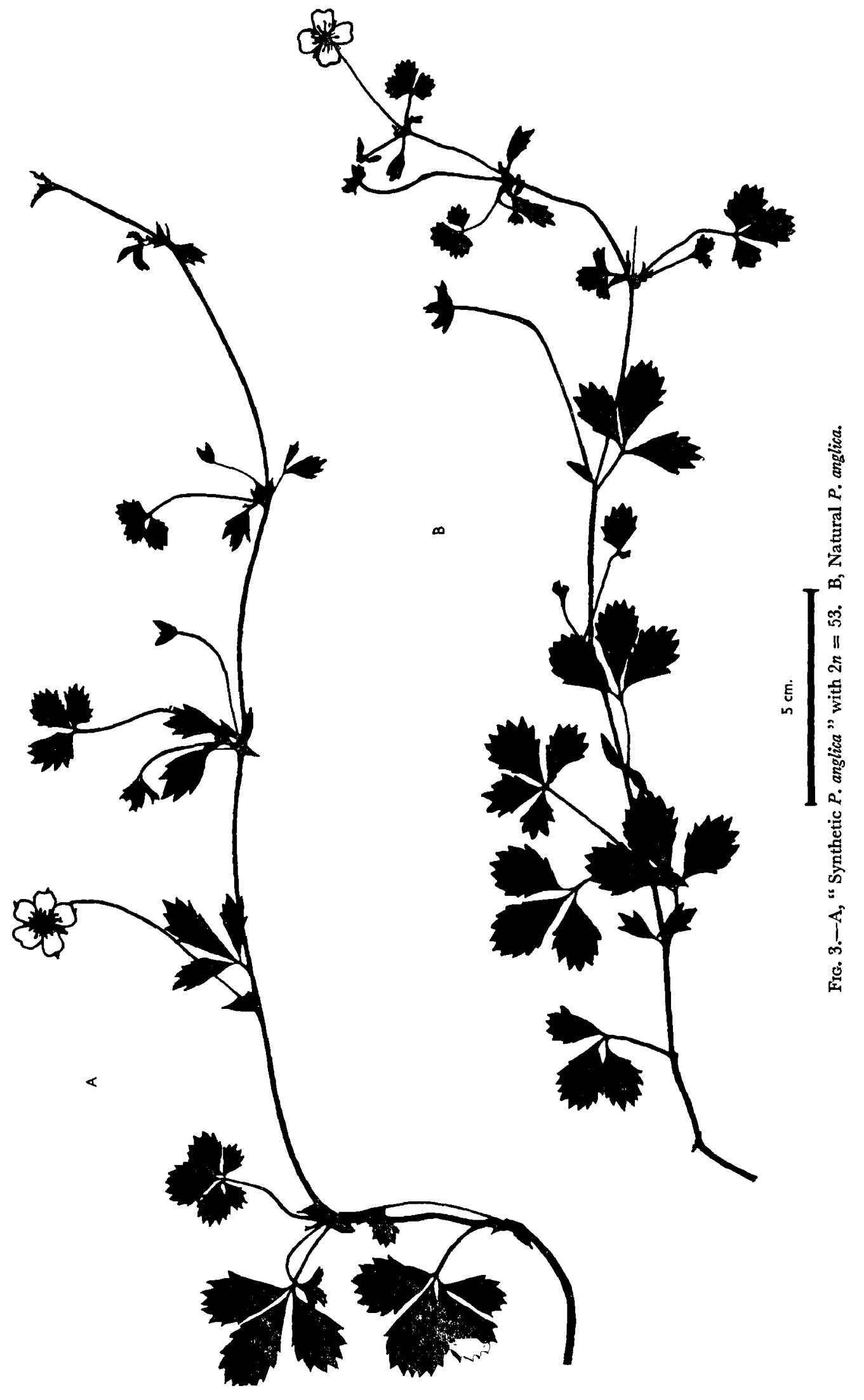


TABLE 6

Fertility of the hypo-octoploid progeny from the cross between auto-8x P. reptans and auto- $6 \times \mathrm{X}$. erecta

$\begin{array}{ccccc}\text { Plant no. } & 2 n & \begin{array}{c}\text { Average percentage } \\ \text { of stainable } \\ \text { pollen }\end{array} & \begin{array}{c}\text { Average seed } \\ \text { number per } \\ \text { flower }\end{array} & \begin{array}{c}\text { Average percentage } \\ \text { of carpels } \\ \text { forming seeds }\end{array} \\ 1 & 52 & 71 & 11 & 39 \\ 2 & 52 & 83 & 39 & 80 \\ 3 & 53 & 57 & 17 & 56 \\ 4 & 54 & 66 & 34 & 70 \\ 5 & 54 & 60 & 25 & 60 \\ 6 & 54 & 72 & 24 & 53 \\ 7 & 55 & 74 & 21 & 67 \\ 8 & 55 & 72 & 20 & 44 \\ 9 & 55 & 55 & 20 & \end{array}$

Meiosis was examined in two plants, with $2 n=53$ and $2 n=54$. Since both were aneuploids, with less than the full octoploid chromosome complement, their pollen mother cells were expected to contain three and two univalents respectively. Table 7 shows that, apart from these univalents, pairing was very regular and very similar to that in $P$. anglica. A few cells contained a trivalent or a quadrivalent and one cell had two univalents in

TABLE 7

Meiosis in hybrids between auto-8x P. reptans and auto- $6 \times$ P. erecta

$$
\begin{array}{r}
2 n=53\left\{\begin{array}{lc}
\text { Chromosome pairing } & \text { Number of P.M.C.s } \\
24 \text { II + 5 I } & 1 \\
25 \text { II + 3 I } & 45 \\
23 \text { II + 1 IV +3 I } & 3
\end{array}\right. \\
2 n=54\left\{\begin{array}{lc}
26 \text { II +2 I } & 35 \\
24 \text { II }+ \text { I IV }+2 \text { I } & 4 \\
25 \text { II + I III + I I } & 3
\end{array}\right.
\end{array}
$$

addition to the expected three. Plate I, E shows diakinesis in the plant with $2 n=54$, with 26 bivalents and two univalents.

The nine hypo-octoploids were so similar to $P$. anglica in morphology, fertility and meiotic behaviour that they could be regarded as "synthetic $P$. anglica". One of them, with $2 n=53$, was crossed reciprocally with the natural species. The pollinations were all successful (table 8 ) and about

TABLE 8

Crosses between "synthetic $\mathbf{P}$. anglica" with $2 n=53$ and natural $\mathbf{P}$. anglica

Number of Average

Number of successful seed Total

flowers pollina- number seed Percentage

9 pollinated tions per flower number germination

"Synthetic Natural

$\begin{array}{lllll}4 & 4 & 32 \cdot 2 & 129 & 43\end{array}$

Natural "Synthetic

$P$. anglica $P$. anglica"

$\begin{array}{lll}4 & 9.7 & 39\end{array}$

69 
half of the seeds had germinated at the time of writing. The progeny were vigorous and fairly uniform in appearance although their chromosome numbers varied (table 9 ). When the aneuploid "synthetic $P$. anglica" was

\section{TABLE 9}

Chromosome numbers of hybrids between " synthetic $\mathrm{P}$. anglica" with

$2 \mathrm{n}=53$ and natural $\mathrm{P}$. anglica

Number of plants with "synthetic

Chromosome number

$P$. anglica" as $q$ parent

Number of plants with natural $P$. anglica as $q$ parent

$\begin{array}{rrrrrc}r 52 & 53 & 54 & 55 & 56 & \text { Total } \\ 1 & 6 & 8 & 3 & 0 & 18 \\ 0 & 1 & 2 & 3 & 3 & 9\end{array}$

used as seed parent, the chromosome numbers of the offspring ranged from $2 n=52$ to $2 n=55$, but when the same plant acted as pollen parent the range was $2 n=53$ to $2 n=56$. The functional pollen grains must therefore have contained more chromosomes than the ovules, presumably as a result of stronger selection pressures on the independent male gametophyte.

The hybrids between "synthetic $P$. anglica" and the natural species were as fertile as their parents. Meiosis was examined in 27 cells from two plants with $2 n=56$. Quadrivalents and univalents were occasionally present but otherwise there was regular bivalent pairing (table 10). Seeds

TABLE 10

Meiosis in octoploid hybrids between natural and synthetic $\mathrm{P}$. anglica

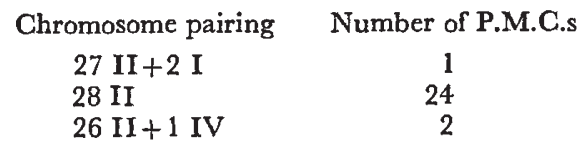

27

collected after open pollination gave a high frequency of germination and all the seedlings were vigorous.

\section{Discussion}

The hybridisations reported in this paper have shown that fertile hybrids similar in morphology to the octoploid species $P$. anglica can be synthesised from the tetraploid species $P$. erecta and $P$. reptans. The chromosome numbers of these hybrids ranged from $2 n=52$ to $2 n=55$, but a euploid, with $2 n=56$, was not obtained in the small progeny raised. The experimental 
(with no signs of degeneration). These results demonstrated that the natural octoploid species and the experimental hybrids were genetically similar and thus the allopolyploid origin of $P$. anglica was confirmed. The vigour and morphological uniformity of the hybrid progenies suggested that the genomes of $P$. erecta and $P$. reptans have changed little since the origin of $P$. anglica. Had divergent evolution occurred, genetic segregation might have produced morphological variation or weakness as in the $F_{2}$ generation of the interspecific cross between Gossypium barbadense and $G$. hirsutum which produces a vigorous and fertile $F_{1}$ (Stebbins, 1950).

Natural allopolyploids may arise in several different ways: somatic chromosome doubling may occur in an $\mathrm{F}_{1}$ hybrid as in the case of Primula

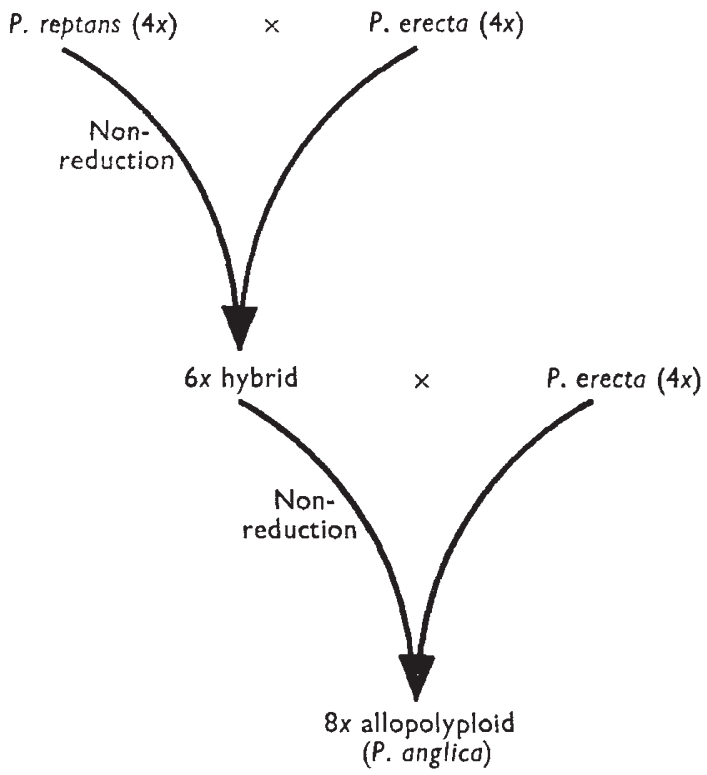

Fig. 4.-The probable origin of $P$. anglica.

kewensis (Newton and Pellew, 1929). Such an origin is possible for $P$. anglica but is considered unlikely because of the apparent absence of natural tetraploid hybrids and the difficulty in hybridising $P$. reptans and $P$. erecta experimentally (Matfield, 1972). Alternatively, the fusion of unreduced gametes or gametes from autopolyploid cytotypes would produce an allopolyploid in a single step. Unreduced gametes have been reported in $P$. reptans (Schwendener, 1969) but not in $P$. erecta and natural autopolyploids are unknown in either species: This origin therefore seems unlikely. A third possibility is for allopolyploidy to arise in two stages, by hybridisation coupled with non-reduction in one parent, followed by a backcross in which the $F_{1}$ hybrid contributes an unreduced gamete. This is similar to Muntzing's (1930) synthesis of the allotetraploid Galeopsis tetrahit from the diploids $G$. pubescens and $G$. speciosa via a triploid hybrid. In case of $P$. anglica the parental species are tetraploids and the intermediate hybrid would therefore be a hexaploid. This appears to be the most likely origin and is illustrated in fig. 4. 
Schwendener (1969) obtained two hexaploids from crosses between $4 x$ $P$. reptans and $4 \times P$. erecta which he considered had arisen by spontaneous non-reduction in $P$. reptans. Morphologically similar hexaploid hybrids known as $P . \times$ mixta also occur naturally. All these $6 x$ hybrids are vigorous, spread by runners and are highly but not completely sterile. Schwendener (1969) pollinated one of the natural hexaploids with $P$. erecta and obtained three offspring one of which was octoploid. This plant, which resulted from non-reduction in the hybrid, was very similar to $P$. anglica in morphology, fertility and meiotic pairing. This demonstrates the feasibility of the evolutionary pathway shown in fig. 4.

However, it cannot be assumed that all the natural hybrids assigned to $P . \times$ mixta have originated by hybridisation between $P$. reptans and $P$. erecta. This is because genomically equivalent hybrids could arise subsequent to the origin of $P$. anglica by backcrossing between $P$. anglica and $P$. reptans.

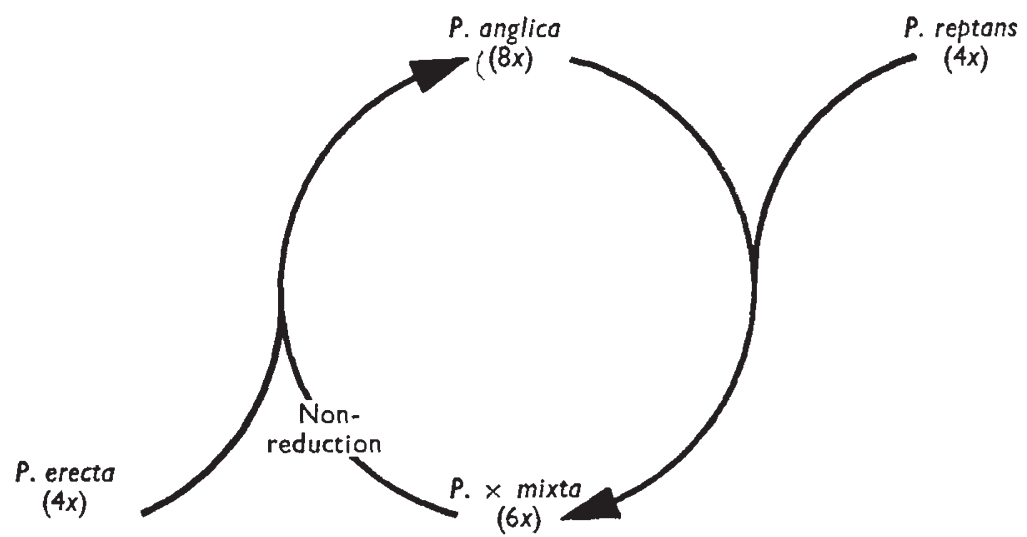

FIG. 5.-A cycle showing the sequence in which the genomes of $P$. reptans and $P$. erecta may be incorporated into $P$. anglica.

This hybrid has been synthesised by Valentine (personal communication) and Matfield (unpublished data) although many previous attempts to hybridise $P$. anglica and $P$. reptans failed (Matfield, Jones and Ellis, 1970). A novel situation may therefore exist in the European Tormentillae in that the same hybrid, $P . \times$ mixta, may arise from different parental species $(P$. reptans $\times P$. anglica or $P$. reptans $\times P$. erecta). In addition, the allopolyploid may not be genetically isolated from the progenital species. The experimental results have demonstrated the feasibility of the cyclical process shown in fig. 5 which would result in $P$. anglica repeatedly incorporating fresh genomes from the tetraploids. This would account for the observed lack of differentiation between the genomes of $P$. erecta and $P$. reptans and the corresponding genomes in the allo-octoploid.

The high degree of meiotic pairing in the tetraploid hybrid between $P$. reptans and $P$. erecta indicates that the genomes of the two species are homoeologous, provided that pairing is allosyndetic. This assumption is justified by earlier observations on meiotic pairing in hexaploid hybrids between $P$. reptans and $P$. anglica (Matfield, unpublished data) and between $P$. anglica and $P$. erecta (Matfield, 1968) which showed that little or no autosyndesis occurs in either the $P$. reptans or the $P$. erecta genomes. The 
constituent genomes of $P$. anglica are therefore homoeologous, but at meiosis bivalents are predominantly formed and quadrivalents occur with a low but variable frequency. $P$. anglica therefore behaves as a segmental allopolyploid as defined by Stebbins (1947) and exhibits preferential pairing. Primula kewensis is a well-known example of this type of polyploid. The $\mathrm{F}_{1}$ hybrid, Primula verticillata $\times P$. floribunda, has a more irregular meiosis than the corresponding Potentilla hybrid, with 2-4 unpaired chromosomes in each cell. However, the allopolyploid Primula kewensis has a higher multivalent frequency than $P$. anglica, forming 1-3 quadrivalents per cell together with an occasional trivalent (Upcott, 1940). The homology between the $P$. reptans and $P$. erecta genomes therefore appears greater than that between the two Primulas, as shown by bivalent formation in the $F_{1}$ hybrid. Despite this, multivalent formation is less frequent in Potentilla anglica than in Primula kewensis. The reason for the high incidence of preferential pairing in $P$. anglica is not known. The low quadrivalent frequency in the raw auto-octoploid $P$. reptans suggests that multivalent formation may be limited by factors such as small chromosome size or low chiasma frequency. However, it is difficult to reconcile this explanation with the very high trivalent frequency in auto-6x P. erecta. Furthermore, Morrison and Rajhathy (1960) found no correlation between quadrivalent frequency and chromosome size in a survey of the meiotic behaviour of a number of autopolyploids. Thus $P$. anglica provides an example of a segmental allopolyploid with preferential pairing, though the mechanism by which this is achieved is unknown.

\section{Summary}

1. Crosses between autopolyploid strains of $P$. reptans and $P$. erecta have produced fertile hybrids similar in morphology and meiotic behaviour to $P$. anglica and interfertile with it. The allopolyploid origin of $P$. anglica has thus been confirmed.

2. Meiotic observations have shown that $P$. anglica is a segmental allopolyploid with a low incidence of multivalent formation.

3. A two stage evolutionary origin is proposed for $P$. anglica in which the hexaploid hybrid $P . \times m i x t a$ is formed as an intermediate step.

4. It is suggested that the allo-octoploid, $P$. anglica may not be genetically isolated from its tetraploid progenitors.

\section{REFERENCES}

BRÜxss, z. 1931. Untersuchungen über die hybridogene Herkunft der Potentilla procumbens Sibth. Acta Horti Bot. Univ. Latv., 5, 194-198.

GRenIER, M. C. 1865. Flore de la Chaine Jurassique. Part 1. Paris.

MATfield, B. 1968. Ph.D. Thesis. University of London.

MATfield, B. 1972. Potentilla reptans L.--Identification of its hybrids. Watsonia (in the press).

MATFIELD, B., JONES, J. x., AND ELlis, J. R. 1970. Natural and experimental hybridization in Potentilla. New Phytol., 69, 171-186.

MORRISON, J. W., AND RAJHATHY, T. 1960. Frequency of quadrivalents in autotetraploid plants. Nature, 187, 528-530.

MUNTZING, A. 1930. Uber Chromosomenvermehrung in Galeopsis-Kreuzungen und ihre Phylogenetische Bedeutung. Hereditas, 14, 153-172.

Newton, W. C. F., AND Pellew, c. 1929. Primula kewensis and its derivatives. J. Genet., $20,405-462$. 


\section{Plate I}

A, Metaphase 1 in auto-8x $P$. reptans showing one quadrivalent (arrowed) and several secondary associations.

B, Metaphase 1 in auto-6x $P$. erecta with 12 trivalents, 2 bivalents (double arrows) and 2 univalents (single arrows).

$\mathrm{C}$, Diakinesis in natural $P$. anglica with one quadrivalent (arrowed).

D, Diakinesis in the $4 x$ hybrid between $P$. reptans and $P$. erecta, showing 13 bivalents and 2 univalents (arrowed).

E, Diakinesis in "synthetic $P$. anglica" with $2 n=54$ showing 26 bivalents and 2 univalents (arrowed).

F, Somatic metaphase in "synthetic $P$. anglica" with $2 n=53$. 


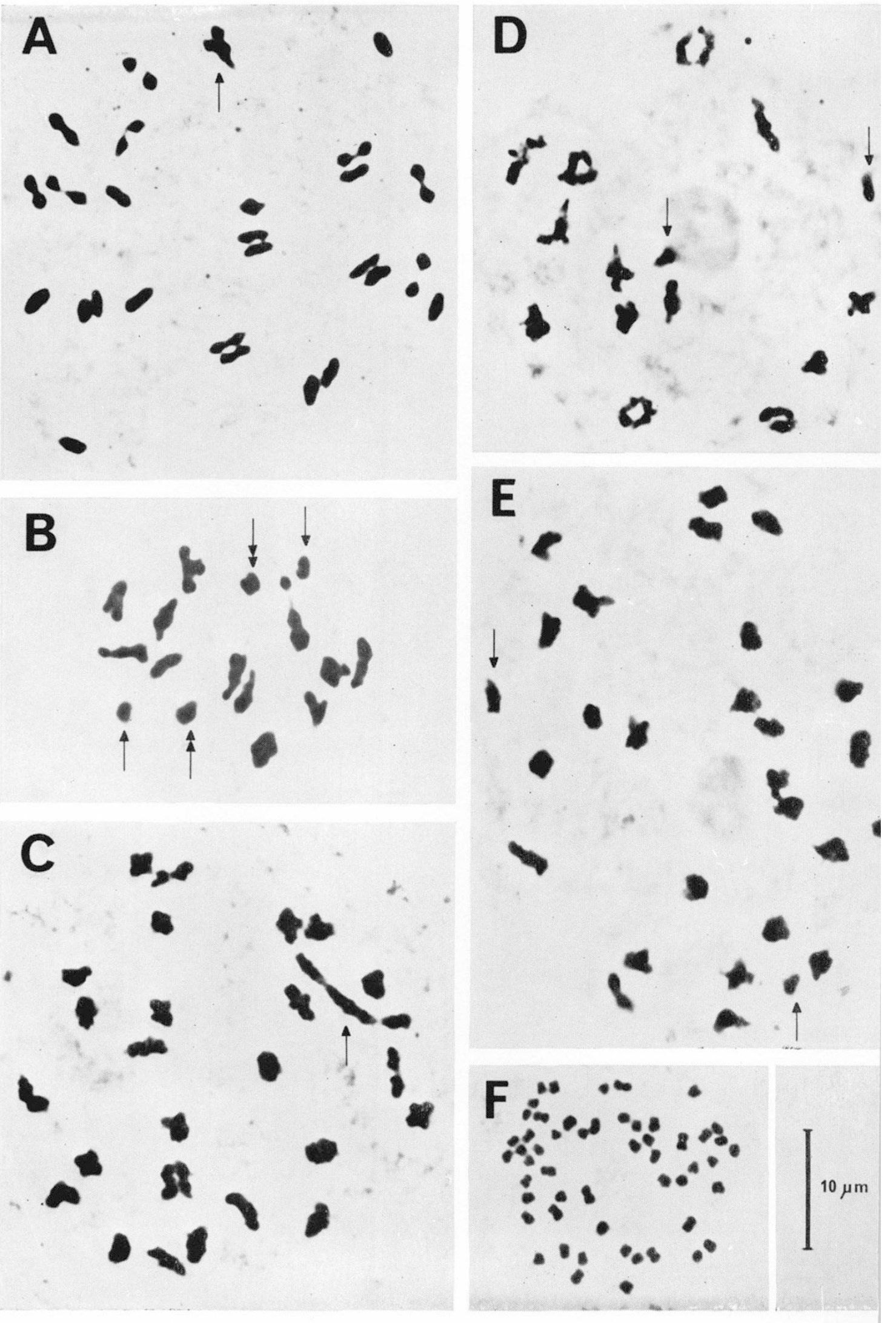


schwendener, J. 1969. Experimente zur Evolution von Potentilla procumbens Sibth. Ber. der Schweiz. Bot. Ges., 79, 49-92.

STEbbins, G. L. 1947. Types of polyploids: their classification and significance. Advances in Genetics, 1, 403-429.

stebbins, G. L. 1950. Variation and Evolution in Plants. New York.

stomps, T. J. 1951. Potentilla anglica Laich. ein neues Beispiel eines allopolyploiden Bastards. Abstract in Proc. Bot. Soc. Brit. Isles, 1, 197.

тномas, P. т. 1940. The aceto-carmine method for fruit material. Stain Tech., 15, 167-172. upcotт, м. 1940. The nature of tetraploidy in Primula kewensis. 7. Genet., 39, 79-100.

wolf, T. 1901. Potentillen-Studien. 1. Dresden.

wOlF, T. 1908. Monographie der Gattung Potentilla. Stuttgart.

\section{Appendix}

Sources of

material:

P. erecta $\left\{\begin{array}{l}\text { Northwood, Middlesex } \\ \text { Thursley, Surrey } \\ \text { Langdale, Westmorland } \\ \text { Aberystwyth, Cardiganshire } \\ \text { Lisdoonvarna, Go. Clare }\end{array}\right.$

Grid ref.

TQ 097898

SU 899416

NY 284056

SN 629837

Ireland 1196

$P$. reptans $\left\{\begin{array}{l}\text { Pinner, Middlesex } \\ \text { Chesil Bank, Dorset } \\ \text { Lea Valley, Essex } \\ \text { Newcastle upon Tyne, Northumberland } \\ \text { Monks Wood, Huntingdonshire } \\ \text { Gounty Durham }\end{array}\right.$

TQ 127885

SY 495885

Unknown

Unknown

TL 188805

Unknown

$P$. anglica $\left\{\begin{array}{l}\text { St John's Wood, London } \\ \text { Arley, Cheshire } \\ \text { Aberystwyth, Cardiganshire } \\ \text { Cumberland }\end{array}\right.$

TQ 272828

SJ 673810

SN 629837

Unknown 